\title{
Association of interleukin-10 -1082 A/G (rs1800896) polymorphism with susceptibility to gastric cancer: meta-analysis of 6,101 cases and 8,557 controls
}

\author{
Abolfazl NAMAZI ${ }^{1}$, Mohammad FORAT-YAZDI ${ }^{1}$, Mohammadali JAFARI ${ }^{2}$, Soudabeh FARAHNAK ${ }^{3}$, \\ Rezvan NASIRI ${ }^{4}$, Elnaz FOROUGHI ${ }^{5}$, Seyed Mojtaba ABOLBAGHAEI ${ }^{6}$ and Hossein NEAMATZADEH ${ }^{7}$
}

ABSTRACT - Background - The promoter -1082 A/G (rs1800896) polymorphism of Interleukin-10 (IL-10) gene have been widely reported and considered to have a significant role on gastric cancer risk, but the results are inconsistent. Objective - To clarify the association, we conducted a meta-analysis to investigate the associations IL-10 -1082 A/G polymorphism with gastric cancer. Methods - Eligible articles were identified by searching databases including PubMed, Web of Science, and Google Scholar up to August 03, 2017. Odds ratios (OR) with corresponding 95\% confidence intervals (CIs) were used to assess the association. Results - A total of 30 case-control studies with 6,101 cases and 8,557 controls were included in this meta-analysis. Overall, a significant association between IL-10 -1082 A/G polymorphism and gastric cancer risk was observed under the allele model (G vs A: $\mathrm{OR}=1.305,95 \% \mathrm{CI}=1.076-1.584 ; P=0.007$ ), heterozygote model and (GA vs AA: $\mathrm{OR}=1.252,95 \% \mathrm{CI}=1.252-1.054 ; P=0.011)$ and dominant model $(\mathrm{GG}+\mathrm{GA}$ vs $\mathrm{AA}: \mathrm{OR}=1.264,95 \% \mathrm{CI}=1.053-1.516 ; P=0.012)$. In the subgroup analysis by ethnicity, increased gastric cancer risk were found in Asians under the allele model ( $\mathrm{G}$ vs $\mathrm{A}: \mathrm{OR}=1.520,95 \% \mathrm{CI}=1.172-1.973 ; P=0.002)$, homozygote model $(\mathrm{GG}+\mathrm{GA}$ vs $\mathrm{AA}: \mathrm{OR}=1.571,95 \% \mathrm{CI}=1.023-$ 2.414; $P=0.039$ ), heterozygote model (GA vs AA: $\mathrm{OR}=1.465,95 \% \mathrm{CI}=1.192-1.801 ; P \leq 0.001)$ and dominant model $(\mathrm{GG}+\mathrm{GA}$ vs AA: $\mathrm{OR}=1.448$, $95 \% \mathrm{CI}=1.152-1.821 ; P=0.002)$, but not among Caucasian and Latinos populations. Conclusion - These results suggested that the IL-10 - $1082 \mathrm{~A} / \mathrm{G}$ (rs1800896) polymorphism might contribute to the gastric cancer susceptibility, especially among Asians.

HEADINGS - Stomach neoplasms. Interleukin-10. Genetic polymorphism. Meta-analysis.

\section{INTRODUCTION}

In the recent years, many exciting discoveries regarding the genomics of gastric cancer have been made, but it remains a major health problem as a result of the population growth, ageing, high mortality and poor prognosis for this disease ${ }^{(1-3)}$. The incidence of gastric cancer varies considerably according to age, gender, socioeconomic conditions and ethnicity, and despite some of the highest risk populations are in Asian countries such as Japan, Korea and China, other Asian countries present relatively low rates ${ }^{(4-6)}$.

To date, the etiology of gastric cancer is still not fully understood $^{(7)}$. It is well known that environmental factors such as dietary habits, Helicobacter pylori (H. pylori) infection, tobacco smoking, and alcohol consumption are more important than genetics in the development and progression of gastric cancer ${ }^{(1-3,8)}$. However, only $1 \%-5 \%$ of individuals with the bacteria actually develop gastric cancer and the pathogenesis is dependent on bacterial strain virulence, host genetic susceptibility and environmental factors ${ }^{(9)}$. Among human cancers, gastric carcinogenesis appears to be a complex multistep processes. Diverse array of genetics factors including functional polymorphisms, chromosomal instability, microsatellite instability, promoter methylation, and abnormal microRNA expression play important roles in gastric cancer carcinogenesis ${ }^{(10)}$.

Interleukin-10 (IL-10) is an important immunoregulatory cytokine which plays a key role in controlling the balance between cellular and humoral immune responses ${ }^{(11)}$. Previous studies have presented evidence that IL-10 may inhibit tumor development and progression ${ }^{(12)}$. It has been reported that the $-1082 \mathrm{~A} / \mathrm{G}$ polymorphism at promoter region of the IL-10 gene may influence this cytokine production and to be associated with the risk of different malignancies including cervical cancer ${ }^{(13)}$, esophageal cancer, nasopharyngeal cancer, oral cancer ${ }^{(14)}$, colon cancer ${ }^{(15)}$, and hepatocellular carcinoma ${ }^{(16)}$. However, the precise mechanism by which the between IL-10 polymorphisms may modulate cancer progression remains unknown ${ }^{(11,12)}$.

Over the past 2 decades, several epidemiological studies have reported the role of IL-10 -1082 A/G (rs1800896) polymorphism

Declared conflict of interest of all authors: none

Disclosure of funding: no funding received

${ }^{1}$ Department of Internal Medicine, Shahid Sadoughi University of Medical Sciences, Yazd, Iran; ${ }^{2}$ Department of Emergency Medicine, Shahid Sadoughi University of Medical Sciences, Yazd, Iran: ${ }^{3}$ Department of Endodontic, Arak University of Medical Sciences, Arak, Iran. ${ }^{4}$ Department of Pediatric Dentistry, Arak University of Medical Sciences, Arak, Iran. 5 Department of Restorative and Esthetic, Arak University of Medical Sciences, Arak, Iran; ${ }^{6}$ Department of Forensic Medicine, Shahid Beheshti University of Medical Sciences, Tehran, Iran; ${ }^{7}$ Mother and Newborn Health Research Center, Shahid Sadoughi University of Medical Sciences, Yazd, Iran.

Correspondence: Mohammad Forat-Yazdi. Department of Internal Medicine, Shahid Sadoughi University of Medical Sciences, Yazd, Iran. E-mail: mohammad.foratyazdi@gmail.com 
in gastric cancer development ${ }^{(17)}$. However, the results were inconsistent rather than conclusive, as result of the small sample size in the most of studies. While meta-analysis is considered a powerful tool for combining data from all eligible studies with more statistical power and obtaining precise estimates. Therefore, we conducted a meta-analysis of all available case-control studies to derive a more precise estimation of the association between of IL-10 -1082 A/G (rs1800896) polymorphism and gastric cancer risk. In addition, current meta-analysis analyzed available data to explore any role of ethnicity and studies quality on the association of IL-10 -1082 A/G (rs1800896) polymorphism in gastric cancer risk.

\section{METHODS}

\section{Study identification and selection}

A systematic literature search was performed for the relevant available studies published in PubMed, Web of Science, Chinese Biomedical Literature database, China National Knowledge Infrastructure database and google scholar up to August 1, 2017. The search strategy identified the eligible studies using the following keywords: "Interleukin-10", "IL-10", "'-1082 A/G", "rs1800896", "polymorphism", "genotype", "variant", "mutation", 'gastric cancer", and "stomach cancer". Additionally, the reference lists of retrieved studies, review articles, clinical trials and previous meta-analyses, were manually searched for collecting more relevant studies that was missed in the electronic search.

\section{Eligibility criteria}

The following inclusion criteria were used in selecting literature for meta-analysis: (a) evaluation of the association between IL-10 -1082 A/G (rs1800896) polymorphism and gastric cancer; (b) studies with case-control or cohort design; (c) sufficient published data for calculating odds ratios (ORs) with their $95 \%$ confidence intervals (95\% CIs); and (d) publications in English and Chinese. If multiple studies from the same data were available, only the most recent, larger sample size or complete study was selected. The studies were excluded (a) only abstracts, review articles, case reports, letter to editors or editorials; (b) not designed as case-control or cohort studies; (c) not offering essential data; (d) control group not including healthy induvial; (e) duplicate of previous published articles.

\section{Data extraction and quality assessment}

The following data of eligible studies were collected by two investigators independently if available: first author, year of publication, country origin, ethnicity, total number of cases and controls, the frequencies of genotypes, genotyping technique, minor allele frequencies (MAFs), $P$-value for Hardy-Weinberg equilibrium (HWE). In case of disagreement, consensus was obtained by discussion, or a third author would assess these articles. The quality of selected studies was tested by the confirmation of HWE in control groups, and studies without the confirmation of HWE in controls were defined as low-quality studies, while studies with the confirmation of HWE in controls were defined as high-quality studies.

\section{Statistical analysis}

The strength of the association between the IL-10 -1082 A/G (rs1800896) polymorphism and gastric cancer risk was measured by crude odds ratios (ORs) with 95\% confidence intervals (CIs).
Pooled estimates of the OR were obtained by calculating a weighted average of OR from each study. The statistical significance of the pooled OR was determined using the Z-test. The meta-analysis examined the IL-10 -1082 A/G (rs1800896) polymorphism association under the allele model ( $\mathrm{G}$ vs A), the homozygote model ( $\mathrm{GG}$ vs AA), homozygote model (GA vs AA), heterozygote model and (GA vs AA), dominant model (GG+GA vs AA), and recessive model (GG vs GA+AA). The Q-statistic and the $\mathrm{I}^{2}$-statistic were used to assess the heterogeneity between studies in the meta-analysis. $\mathrm{I}^{2}$ was a value describe the degree of heterogeneity between studies, where $0-25 \%$ indicated no observed heterogeneity and larger values showed increasing heterogeneity, with $25 \%-50 \%$ regarded as low, $50 \%-75 \%$ as moderate, and $75 \%-100 \%$ as high ${ }^{(18,19)}$. A $P$-value greater than 0.10 for the Q-statistic indicates a lack of heterogeneity between studies, so the pooled OR estimate of the included studies was calculated by the fixed-effects model (MantelHaenszel method) ${ }^{(20)}$. Otherwise, the random-effects model (the DerSimonian and Laird method) was used ${ }^{(21)}$. The heterogeneity between studies was adjusted by subgroup analysis, HWE status and meta-regression. Departure from Hardy-Weinberg equilibrium (HWE) in controls was tested by the chi-square test, and a $P$-value $<0.05$ was considered significant. One-way sensitivity analyses were performed to assess the stability of the results, namely, a single study in the meta-analysis was deleted each time to reflect the influence of the individual dataset on the pooled OR. Funnel plots and Egger's linear regression test were used to provide diagnosis of the potential publication bias $^{(22,23)}$. To ensure reliability and accuracy of the results, two investigators entered the data into the software independently and reached a consensus. All statistical analyses were performed by using Comprehensive Meta-Analysis software version 2.20 (Stata Corp., College Station, TX, USA). All the $P$ values were two-sided, and a $P$ value less than 0.05 was considered statistically significant.

\section{RESULTS}

Based on the search criteria and manual search of references cited in the published case-control studies and meta-analyses, 67 individual articles were found. After screening the titles and abstracts, 29 articles were excluded because they were not relevant to the association of IL-10 -1082 A/G polymorphism with risk of gastric cancer. After reading the full texts of the remaining 37 articles, we found one article had not sufficient data of genotype for calculating OR and 95\% CI, four articles were meta-analyses, and two articles were reviews. Finally, a total of 30 studies $^{(4-7,10-14,16-20,24-39)}$ published from 2002 and 2015 with 6,101 cases and 8,557 controls met our inclusion criteria. The main characteristics of these studies were listed in TABLE 1 . Among the 31 case-control studies, there were 21 studies of Asians ${ }^{(24-30,33-46)}$, six studies of Caucasians ${ }^{(47-52)}$, and three studies of Latinos ${ }^{(53,54,32)}$ descendants. The countries of these studies included China, Korea, Japan, Taiwan, India, USA, Italy, Finland, Spain, Romania, Costa Rica, Honduras and Chile. All the genotype distributions of controls were in agreement with HWE for IL-10 -1082 A/G polymorphism except for eleven stu$\operatorname{dies}^{(27,29,30,34,38,41,42,45-47,49)}$. Twenty of 31 studies were in accordance with HWE and were therefore defined as high-quality studies (TABLE 1).

\section{Quantitative data synthesis}

The main results of this meta-analysis were listed in TABLE 2 
TABLE 1. Main characteristics of studies included in this meta-analysis

\begin{tabular}{|c|c|c|c|c|c|c|c|c|c|c|c|c|c|c|c|}
\hline \multirow{3}{*}{$\begin{array}{l}\text { First author } \\
-1082 \mathrm{~A} / \mathrm{G}(\mathrm{rs} 1800896)\end{array}$} & \multirow{3}{*}{$\begin{array}{l}\text { Country } \\
\text { (Ethnicity) }\end{array}$} & \multirow{3}{*}{$\begin{array}{l}\text { Case } \\
6101\end{array}$} & \multirow{3}{*}{$\begin{array}{c}\text { Control } \\
8557 \\
\end{array}$} & \multicolumn{5}{|c|}{ Cases } & \multicolumn{5}{|c|}{ Controls } & \multirow{3}{*}{ MAFs } & \multirow{3}{*}{ HWE } \\
\hline & & & & \multicolumn{3}{|c|}{ Genotypes } & \multicolumn{2}{|c|}{ Allele } & \multicolumn{3}{|c|}{ Genotypes } & \multicolumn{2}{|c|}{ Allele } & & \\
\hline & & & & AA & $\mathrm{AG}$ & GG & A & G & AA & AG & GG & A & G & & \\
\hline$\overline{\text { Wu } 2002^{(37)}}$ & China (Asian) & 150 & 220 & 135 & 14 & 1 & 284 & 16 & 208 & 11 & 1 & 427 & 13 & 0.029 & 0.057 \\
\hline El-Omar $2003^{(48)}$ & USA (Caucasian) & 314 & 210 & 120 & 133 & 61 & 373 & 255 & 59 & 103 & 48 & 221 & 199 & 0.473 & 0.812 \\
\hline Savage $2004^{(34)}$ & China (Asian) & 84 & 382 & 4 & 20 & 60 & 28 & 140 & 20 & 81 & 284 & 120 & 644 & 0.842 & $\leq 0.001$ \\
\hline Lee $2005^{(28)}$ & Korea (Asian) & 122 & 120 & 104 & 17 & 1 & 225 & 19 & 101 & 18 & 1 & 220 & 20 & 0.083 & 0.842 \\
\hline Lu $2005^{(30)}$ & China (Asian) & 250 & 300 & 201 & 43 & 6 & 445 & 55 & 268 & 29 & 3 & 565 & 35 & 0.058 & 0.037 \\
\hline Alpízar-Alpízar 2005(53) & Costa Rica (Latinos) & 45 & 44 & 45 & 0 & 0 & 90 & 0 & 43 & 1 & 0 & 87 & 1 & 0.011 & 0.939 \\
\hline Morgan $2006^{(32)}$ & Honduras (Latinos) & 170 & 162 & 121 & 42 & 7 & 284 & 56 & 101 & 49 & 11 & 253 & 71 & 0.220 & 0.145 \\
\hline Kamangar $2006^{(51)}$ & Finland (Caucasian) & 112 & 208 & 38 & 47 & 27 & 123 & 101 & 72 & 96 & 37 & 244 & 172 & 0.414 & 0.613 \\
\hline Sugimoto $2007^{(36)}$ & Japan (Asian) & 105 & 168 & 78 & 26 & 0 & 184 & 26 & 134 & 34 & 0 & 302 & 34 & 0.101 & 0.144 \\
\hline García $2007^{(50)}$ & Spain (Caucasian) & 404 & 404 & 123 & 204 & 77 & 450 & 358 & 133 & 189 & 82 & 455 & 353 & 0.436 & 0.322 \\
\hline Bai $2008^{(40)}$ & China (Asian) & 111 & 111 & 89 & $22(\mathrm{AG}$ & +GG) & - & - & 104 & $7(\mathrm{AG}$ & +GG) & - & - & - & - \\
\hline Forte $2008^{(49)}$ & Italy (Caucasian) & 42 & 185 & 21 & 16 & 5 & 58 & 26 & 83 & 66 & 36 & 235 & 135 & 0.364 & $\leq 0.001$ \\
\hline He $2012^{(43)}$ & China (Asian) & 196 & 248 & 154 & 42 & 0 & 350 & 42 & 194 & 54 & 0 & 442 & 54 & 0.108 & 0.054 \\
\hline Zeng $2012^{(45)}$ & China (Asian) & 151 & 153 & 27 & 60 & 64 & 114 & 188 & 48 & 53 & 52 & 149 & 157 & 0.513 & $\leq 0.001$ \\
\hline $\operatorname{Kim} 2012^{(23)}$ & Korea (Asian) & 495 & 495 & 416 & 72 & 7 & 904 & $86 w$ & 435 & 56 & 1 & 932 & 58 & 0.058 & 0.564 \\
\hline Chand-Bhayal $2012^{(41)}$ & India (Asian) & 100 & 132 & 47 & 35 & 18 & 129 & 71 & 40 & 50 & 42 & 130 & 134 & 0.507 & 0.005 \\
\hline Pan $2013^{(33)}$ & China (Asian) & 308 & 308 & 263 & 41 & 4 & 567 & 49 & 264 & 41 & 3 & 596 & 47 & 0.076 & 0.329 \\
\hline Kuo $2014^{(27)}$ & Taiwan (Asian) & 358 & 358 & 235 & 101 & 22 & 571 & 145 & 281 & 67 & 10 & 629 & 87 & 0.121 & 0.019 \\
\hline Hormazabal 2014 $4^{(54)}$ & Chile (Latinos) & 147 & 172 & 79 & 54 & 14 & 212 & 82 & 88 & 71 & 13 & 247 & 97 & 0.282 & 0.799 \\
\hline Burada $2010^{(47)}$ & Romania (Caucasian) & 63 & 78 & 9 & 54 & 0 & 72 & 54 & 12 & 66 & 0 & 90 & 66 & 0.423 & $\leq 0.001$ \\
\hline Kumar $2015^{(26)}$ & India (Asian) & 200 & 250 & 74 & 96 & 30 & 244 & 156 & 85 & 122 & 43 & 464 & 36 & 0.071 & 0.945 \\
\hline
\end{tabular}

MAF: minor allele frequencie; HWE: Hardy-Weinberg equilibrium.

TABLE 2. The meta-analysis of IL-10 - $1082 \mathrm{~A} / \mathrm{G}$ polymorphism and gastric cancer risk

\begin{tabular}{|c|c|c|c|c|c|c|c|c|c|c|c|}
\hline \multirow{2}{*}{ Subgroup } & \multirow{2}{*}{ Study number } & \multirow{2}{*}{ Genetic model } & \multirow{2}{*}{$\begin{array}{l}\text { Type of } \\
\text { model }\end{array}$} & \multicolumn{2}{|c|}{ Heterogeneity } & \multicolumn{4}{|c|}{ Odds ratio } & \multicolumn{2}{|c|}{ Publication Bias } \\
\hline & & & & $\mathrm{I}^{2}(\%)$ & $P_{H}$ & OR & $95 \% \mathrm{CI}$ & $Z_{\text {test }}$ & $\mathbf{P}_{\mathrm{OR}}$ & $P_{\text {Beggs }}$ & $\mathbf{P}_{\text {Eggers }}$ \\
\hline \multirow[t]{5}{*}{ Overall } & 29 & G vs. A & Random & 85.89 & $\leq 0.001$ & 1.305 & $1.076-1.584$ & 2.701 & 0.007 & 0.398 & 0.393 \\
\hline & 25 & GG vs. AA & Random & 52.67 & 0.001 & 1.225 & $0.925-1.622$ & 1.416 & 0.157 & 0.107 & 0.118 \\
\hline & 29 & GA vs. AA & Random & 67.95 & $\leq 0.001$ & 1.252 & $1.252-1.054$ & 2.555 & 0.011 & 0.338 & 0.438 \\
\hline & 30 & $\mathrm{GG}+\mathrm{GA}$ vs. AA & Random & 74.13 & $\leq 0.001$ & 1.264 & $1.053-1.516$ & 2.517 & 0.012 & 0.253 & 0.483 \\
\hline & 25 & GG vs. GA+ AA & Random & 39.20 & 0.024 & 1.150 & $0.929-1.425$ & 1.281 & 0.200 & 0.107 & 0.071 \\
\hline \multicolumn{12}{|l|}{ By ethnicity } \\
\hline \multirow[t]{5}{*}{ Caucasian } & 6 & G vs. A & Fixed & 27.54 & 0.228 & 0.975 & $0.867-1.096$ & -0.427 & 0.669 & 1.000 & 0.911 \\
\hline & 5 & GG vs. AA & Fixed & 44.94 & 0.123 & 0.975 & $0.767-1.239$ & -0.208 & 0.835 & 1.000 & 0.814 \\
\hline & 6 & GA vs. AA & Fixed & 13.69 & 0.327 & 0.915 & $0.759-1.104$ & -0.929 & 0.353 & 0.425 & 0.867 \\
\hline & 6 & $\mathrm{GG}+\mathrm{GA}$ vs. AA & Fixed & 32.65 & 0.191 & 0.975 & $0.817-1.164$ & -0.280 & 0.780 & 0.452 & 0.916 \\
\hline & 5 & GG vs. GA+ AA & Random & 52.81 & 0.076 & 1.048 & $0.847-1.297$ & 0.434 & 0.664 & 1.000 & 0.995 \\
\hline \multirow[t]{5}{*}{ Asian } & 21 & G vs. A & Random & 87.13 & $\leq 0.001$ & 1.520 & $1.172-1.973$ & 3.152 & 0.002 & 0.770 & 0.860 \\
\hline & 18 & GG vs. AA & Random & 53.70 & 0.004 & 1.571 & $1.023-2.414$ & 2.063 & 0.039 & 0.225 & 0.198 \\
\hline & 20 & GA vs. AA & Random & 67.76 & $\leq 0.001$ & 1.465 & $1.192-1.801$ & 3.645 & $\leq 0.001$ & 0.314 & 0.272 \\
\hline & 21 & $\mathrm{GG}+\mathrm{GA}$ vs. AA & Random & 76.34 & $\leq 0.001$ & 1.448 & $1.152-1.821$ & 3.173 & 0.002 & 0.349 & 0.400 \\
\hline & 18 & GG vs. GA+ AA & Random & 40.62 & 0.038 & 1.290 & $0.934-1.781$ & 1.547 & 0.122 & 0.129 & 0.056 \\
\hline \multirow[t]{5}{*}{ Latinos } & 3 & G vs. A & Fixed & 0.00 & 0.375 & 0.843 & $0.651-1.091$ & -1.298 & 0.194 & 1.000 & 0.665 \\
\hline & 2 & GG vs. AA & Fixed & 36.06 & 0.211 & 0.862 & $0.460-1.613$ & -0.466 & 0.641 & NA & NA \\
\hline & 3 & GA vs. AA & Fixed & 0.00 & 0.766 & 0.774 & $0.553-1.083$ & -1.494 & 0.135 & 0.296 & 0.442 \\
\hline & 3 & $\mathrm{GG}+\mathrm{GA}$ vs. AA & Fixed & 0.00 & 0.609 & 0.786 & $0.572-1.078$ & -1.493 & 0.135 & 1.000 & 0.604 \\
\hline & 2 & GG vs. GA+ AA & Fixed & 33.01 & 0.222 & 0.944 & $0.512-1.743$ & -0.183 & 0.855 & NA & NA \\
\hline \multicolumn{12}{|c|}{ By studies quality } \\
\hline \multirow[t]{5}{*}{ High quality } & 18 & G vs. A & Random & 88.61 & $\leq 0.001$ & 1.336 & $1.016-1.756$ & 2.071 & 0.038 & 0.129 & 0.361 \\
\hline & 16 & GG vs. AA & Random & 43.12 & 0.034 & 1.225 & $0.892-1.683$ & 1.253 & 0.210 & 0.052 & 0.021 \\
\hline & 19 & GA vs. AA & Random & 71.94 & $\leq 0.001$ & 1.187 & $0.962-1.465$ & 1.596 & 0.110 & 0.441 & 0.699 \\
\hline & 21 & $\mathrm{GG}+\mathrm{GA}$ vs. AA & Random & 73.11 & $\leq 0.001$ & 1.150 & $0.929-1.424$ & 1.286 & 0.198 & 0.263 & 0.570 \\
\hline & 16 & GG vs. GA+ AA & Fixed & 29.33 & 0.130 & 1.060 & $0.890-1.263$ & 0.656 & 0.512 & 0.052 & 0.015 \\
\hline \multirow[t]{5}{*}{ Low quality } & 10 & G vs. A & Random & 79.54 & $\leq 0.001$ & 1.260 & $0.968-1.641$ & 1.721 & 0.085 & 0.755 & 0.790 \\
\hline & 10 & GG vs. AA & Random & 66.60 & 0.001 & 1.268 & $0.754-2.134$ & 0.894 & 0.371 & 0.720 & 0.554 \\
\hline & 11 & GA vs. AA & Random & 54.98 & 0.014 & 1.460 & $1.121-1.902$ & 2.806 & 0.005 & 0.436 & 0.848 \\
\hline & 12 & $\mathrm{GG}+\mathrm{GA}$ vs. AA & Random & 76.86 & $\leq 0.001$ & 1.449 & $1.033-2.033$ & 2.150 & 0.032 & 0.450 & 0.854 \\
\hline & 10 & GG vs. GA+AA & Random & 52.26 & 0.026 & 1.109 & $0.770-1.597$ & 0.555 & 0.579 & 0.858 & 0.932 \\
\hline
\end{tabular}


and FIGURE 1A, 1B. Overall, there was a significant association between IL-10 -1082 A/G polymorphism and gastric cancer in overall under the allele model $(\mathrm{G}$ vs A: $\mathrm{OR}=1.305,95 \% \mathrm{CI}=1.076-$ 1.584; $P=0.007$, FIGURE 1A), the heterozygote model (GA vs $\mathrm{AA}: \mathrm{OR}=1.252,95 \% \mathrm{CI}=1.252-1.054 ; P=0.011)$ and the dominant model $(\mathrm{GG}+\mathrm{GA}$ vs AA: $\mathrm{OR}=1.264,95 \% \mathrm{CI}=1.053-1.516 ; P=0.012$, FIGURE 1B), but not under the homozygote model (GG vs AA: $\mathrm{OR}=1.225,95 \% \mathrm{CI}=0.925-1.622 ; P=0.157)$ and the recessive model $(\mathrm{GG}+\mathrm{GA}$ vs AA: $\mathrm{OR}=1.150,95 \% \mathrm{CI}=0.929-1.425 ; P=0.200)$.

Subgroup analysis of Asians showed that there was a significant association between IL-10 -1082 A/G polymorphism and increased risk of gastric cancer under the allele model $(\mathrm{G}$ vs $\mathrm{A}: \mathrm{OR}=1.520$, $95 \% \mathrm{CI}=1.172-1.973 ; P=0.002$ ), the homozygote model ( $\mathrm{GG}$ vs AA: $\mathrm{OR}=1.571,95 \% \mathrm{CI}=1.023-2.414 ; P=0.039)$, the heterozygote model and $(\mathrm{GA}$ vs $\mathrm{AA}: \mathrm{OR}=1.465,95 \% \mathrm{CI}=1.192-1.801 ; P \leq 0.001)$ and the dominant model $(\mathrm{GG}+\mathrm{GA}$ vs $\mathrm{AA}: \mathrm{OR}=1.448,95 \% \mathrm{CI}=1.152-$ $1.821 ; P=0.002$ ). However, subgroup analysis of Caucasians and Latinos showed that there was no association between IL-10 -1082 $\mathrm{A} / \mathrm{G}$ polymorphism and increased risk of gastric cancer in the Caucasians and Latinos populations (TABLE 2).

Subgroup analysis of studies with high quality showed that there was a significant association between IL-10 -1082 A/G polymorphism and increased risk of gastric cancer only under the allele model $(\mathrm{OR}=1.336,95 \% \mathrm{CI}=1.016-1.756, P=0.038$, TABLE 2). However, in the subgroup analysis of studies with low quality, there was still a significant association between IL-10 -1082 $\mathrm{A} / \mathrm{G}$ polymorphism and increased risk of gastric cancer under heterozygote model (GA vs AA: $\mathrm{OR}=1.460,95 \% \mathrm{CI}=1.121-1.902$; $P=0.005)$ and dominant model $(\mathrm{GG}+\mathrm{GA}$ vs $\mathrm{AA}: \mathrm{OR}=1.449,95 \%$ $\mathrm{CI}=1.033-2.033 ; P=0.032)($ TABLE 2).

\section{Test of heterogeneity and sensitivity analysis}

The heterogeneity test showed that there was significant between-study heterogeneity in terms of the IL-10 -1082 A/G polymorphism in all five genetic models (TABLE 2). Then, we used a meta-regression analysis to explore the source of heterogeneity by Ethnicity and quality of studies. Results showed that ethnicity contribute to substantial heterogeneity. Furthermore, we performed sensitivity analyses to assess the influence of each individual study on the pooled ORs by sequential omission of individual studies, such as the study that did not conform to HWE. However, the corresponding pooled ORs were not materially altered by removing any individual study. Moreover, in all tests the $\mathrm{I}^{2}$ value for heterogeneity did not reduced. Therefore, the sensitivity analysis confirmed that the results of this meta-analysis were statistically reliable and stable.

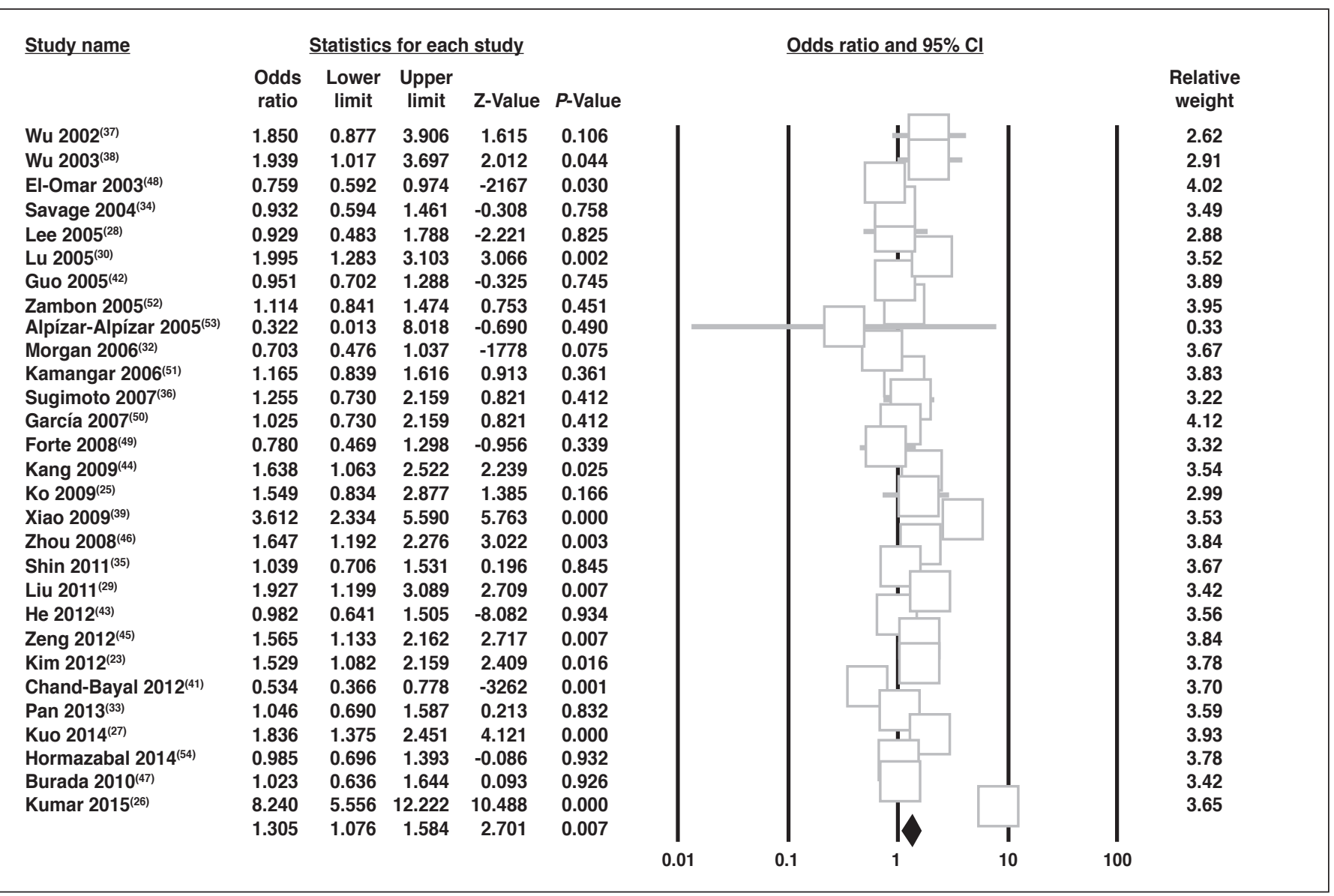

FIGURE 1A. Forest plot of gastric cancer risk associated with the IL-10 -1082 A/G (rs1800896) polymorphism. A. Allele model (G vs A) and B. Dominant model (GG+GA vs. AA). The squares and horizontal lines correspond to the study-specific OR and $95 \% \mathrm{CI}$. The area of the squares reflects the weight (inverse of the variance). The diamond represents the summary OR and $95 \% \mathrm{CI}$. 


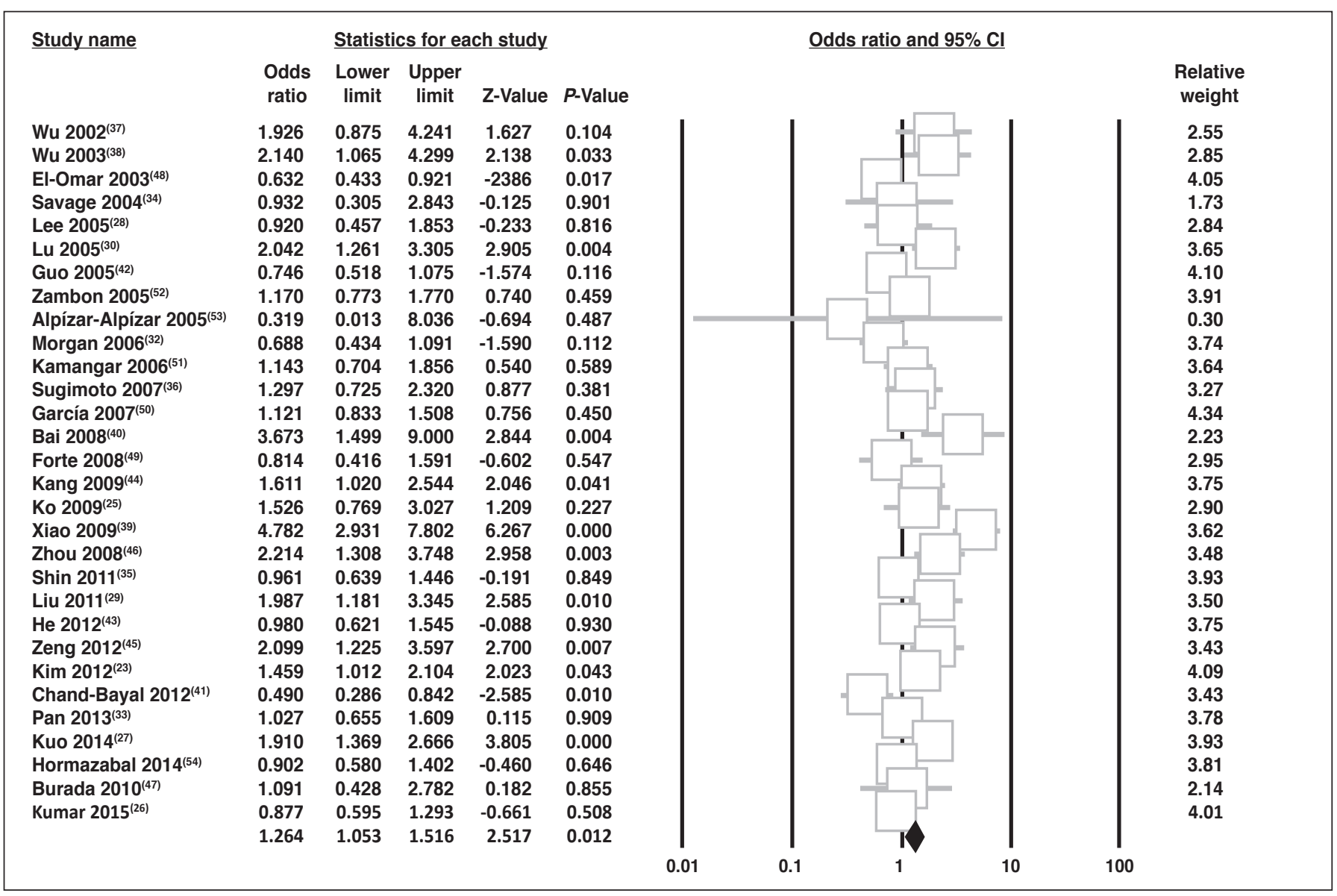

FIGURE 1B. Forest plot of gastric cancer risk associated with the IL-10 -1082 A/G (rs1800896) polymorphism. A. Allele model (G vs A) and B. Dominant model (GG+GA vs. AA). The squares and horizontal lines correspond to the study-specific OR and $95 \% \mathrm{CI}$. The area of the squares reflects the weight (inverse of the variance). The diamond represents the summary OR and 95\% CI.

\section{Publication bias}

Begg's funnel plot and Egger's test were used to assess the potential publication bias in the literature. However, the shape of funnel plots did not reveal any evidence of funnel plot asymmetry (FIGURE 2A, 2B). Then, the Egger's test was used to provide statistical evidence for funnel plot symmetry. The results also provided statistical evidence for the absence of publication bias.

\section{DISCUSSION}

To date, several case-control studies have been reported to evaluate the association between IL-10 -1082 A/G polymorphism and gastric cancer. However, the results were inconsistent and most studies in Caucasian and Latinos populations failed to identify an association with gastric cancer. The current study was not the first

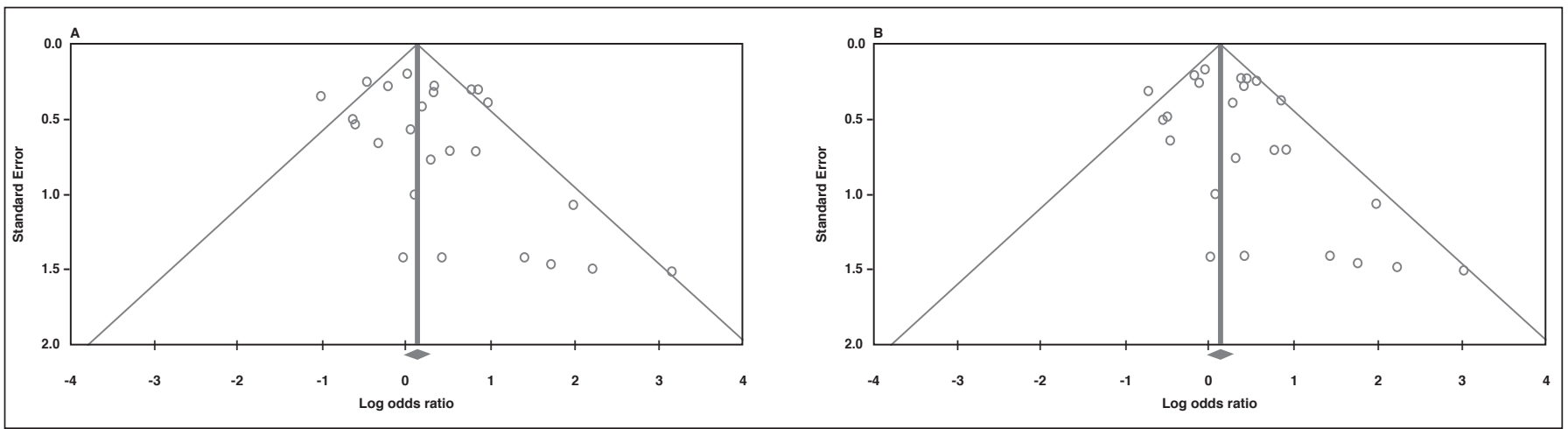

FIGURE 2. Begg's funnel plot of publication bias test. A. The homozygote model (GG vs AA), B. The recessive model (GG vs Ga+ AA). Each point representes a separete study for the indicated association. Log (OR),natural logarithm of OR. Horizontal line, mean effect size. 
meta-analysis aimed to evaluate the associations between IL-10 $-1082 \mathrm{~A} / \mathrm{G}$ polymorphism and gastric cancer. However, the current meta-analysis was the most comprehensive assessment of the association between IL-10 -1082 A/G polymorphism and gastric cancer, which extended the previous meta-analyses with a larger sample size and different subgroups. Additionally, we believe the current meta-analysis is most accurate meta-analysis on the association due to the subgroup analysis by studies quality according to the Hardy-Weinberg equilibrium (HWE) status.

A total of 30 studies with a total of 6431 controls and 3631 cases were eligible for the meta-analysis of IL-10 -1082 A/G polymorphism and gastric cancer. In this meta-analysis, a significant association of the of IL-10 -1082 A/G polymorphism with gastric cancer risk was found under the allele model ( $\mathrm{G}$ vs $\mathrm{A}$ : $\mathrm{OR}=1.305$, 95\% CI=1.076-1.584; $P=0.007$ ), heterozygote model and (GA vs AA: $\mathrm{OR}=1.252,95 \% \mathrm{CI}=1.252-1.054 ; P=0.011)$, dominant model $(\mathrm{GG}+\mathrm{GA}$ vs $\mathrm{AA}: \mathrm{OR}=1.264,95 \% \mathrm{CI}=1.053-1.516 ; P=0.012)$, and in Asians. The inconsistent results between Asians and other ethnicity (Caucasians and Latinos) on subgroup analysis partly may be caused by genetic diversity in different ethnicities. Furthermore, as gastric cancer is a multifactorial disease, except genetic factors, environmental factors play important roles in the pathogenesis of gastric cancer.

We found that the results of our meta-analysis are consistent with a meta-analysis of 20 case-control studies with a total of 3631 cases and 6431 controls published in 2012 by Ni et al. to examine the relationship between IL-10 $-1082 \mathrm{~A} / \mathrm{G}$ polymorphism and gastric cancer ${ }^{(17)}$. They have found that the IL-10 -1082 A/G polymorphism was associated with susceptibility to gastric cancer infection in Asians. However, their study had some limitations should be mentioned. First, they wrongly not included a study by Bai et al., 2008 because they reported only the number of combined group GG+GA rather than the number of genotype GG and GA. Second, they have excluded all studies that deviated from HWE, which it seems publication bias have been occurred at the start of their meta-analysis. However, meta-analyses should report both the magnitude and the statistical significance of deviation from $\mathrm{HWE}^{(40)}$. There is currently no consensus for whether to select eligible studies according to HWE status. In the current metaanalysis the results was different by HWE status or studies quality, it is suggested that the analysis with studies departed from HWE may be more reliable. Third, they have performed some subgroup analyses by sample size and publication before or after 2005, which we suggested unnecessary to do these subgroup analyses. Fourth, their results reliability and the number of studies are considerably smaller than that needed to receive the robust conclusions.

Between-study heterogeneity is inevitable in a meta-analysis ${ }^{(55)}$. Thus, one of the most important goals of the meta-analysis is to identify the source of heterogeneity ${ }^{(56)}$. Basically, between-studies variability and variability due to sampling error are main sources of heterogeneity in a set of studies in a meta-analysis ${ }^{(19,31,55,56)}$. The between-study heterogeneity in the current meta-analysis existed in overall under all genetic models and subgroup analyses in Asians. There was no significant heterogeneity after subgroup analyses among Caucasians and Latinos population. Moreover, after removing the study deviating from HWE, the heterogeneity did not disappear. Thus, the results revealed that studies in Asians may be the major source of heterogeneity in overall models.

The current meta-analysis had several strengths. Most importantly, this is the biggest and most recent meta-analysis of the association between IL-10 -1082 A/G polymorphism and gastric cancer. Therefore, this was more powerful than previous metaanalysis. In addition, a subgroup analysis among mixed population and HWE status was conducted and demonstrated that the IL-10 $-1082 \mathrm{~A} / \mathrm{G}$ polymorphism not significantly associated with gastric cancer risk in Caucasian and mixed populations. Third, we did not detect any publication bias indicating that the whole pooled results should be unbiased.

Despite the clear strength of our study including large sample sizes, some limitations of this meta-analysis should be acknowledged. Second, the overall OR was based on individual unadjusted ORs, and some important confounding factors, such as age, gender, dietary, Helicobacter pylori (H. pylori) infection, tobacco smoking, and alcohol consumption, gastric cancer site (cardia and noncardia) and histological type must be adjusted for. Third, although the funnel plots and Egger's tests showed that publication bias did not affect our results, only published studies published in English or Chinese with sufficient data were included, thus, publication bias may have occurred at the start of current meta-analysis. Finally, lack of original data from origin data in the including studies limited our evaluation of potential gene-gene and gene-environment interactions and even different polymorphic loci of the same gene which may modulate the gastric cancer susceptibility.

In conclusion, this meta-analysis suggests that IL-10 -1082 A/G (rs1800896) polymorphism may be associated with increased gastric cancer risk. Moreover, further studies estimating the effect of gene-gene and gene-environment interactions are necessary to better understanding of the association between the IL-10 -1082 A/G (rs1800896) polymorphism and risk of gastric cancer.

\section{Authors' contributions}

Namazi A, Forat-Yazdi M and Abolbaghaei SM conceived and research design. Farahnak S, Nasiri R, and Foroughi E selected the articles. Neamatzadeh $\mathrm{H}$ and Jafari $\mathrm{M}$ performed data analysis. The manuscript was drafted by Namazi A, Forat-Yazdi $\mathrm{M}$ and Neamatzadeh $\mathrm{H}$ critically reviewed and discussed with the other co-authors. All the authors read and approved the final manuscript. 
Namazi A, Forat-Yazdi M, Jafari M, Farahnak S, Nasiri R, Foroughi E, Abolbaghaei SM, Neamatzadeh H. Associação de interleucina-10-1082 A/polimorfismo G (rs1800896) com suscetibilidade a câncer gástrico: meta-análise de 6.101 casos e 8.557 controles. Arq Gastroenterol. 2018;55(1):33-40.

RESUMO - Contexto - O promotor-1082 A/polimorfismo G (rs1800896) do gene da interleucina-10 (IL-10) é amplamente relatado e considerado por ter um papel significativo no risco de câncer gástrico, porém os resultados são inconsistentes. Objetivo-Para esclarecer melhor esta associação, realizou-se uma meta-análise para investigar as associações de IL-10-1082 A/polimorfismo G com câncer gástrico. Métodos - Artigos elegíveis foram identificados através de pesquisa de bases de dados PubMed, Web of Science e Google Scholar até 3 de agosto de 2017. Razões de possibilidades (OR) com intervalo de confiança de $95 \%$ correspondente (CIs) foram usados para avaliar a associação. Resultados - Um total de 30 estudos de caso-controle, 6.101 casos e com 8.557 controles foram incluídos nesta meta-análise. Em geral, uma associação significativa entre IL-10-1082 A/G polimorfismo e risco de câncer gástrico foi observada sob o modelo de alelo ( $\mathrm{G}$ vs $\mathrm{A}$ : $\mathrm{OR}=1.305,95 \% \mathrm{CI}=1.076-1.584 ; P=0.007)$, no modelo heterozigoto $(\mathrm{GA}$ vs $\mathrm{AA}$ : $\mathrm{OR}=1.252$, $95 \% \mathrm{CI}=1.252-1.054 ; P=0.011)$ e modelo dominante (GG+GA vs AA: $\mathrm{OR}=1.264,95 \% \mathrm{CI}=1.053-1.516 ; P=0.012$ ). Na análise de subgrupo pela etnia, foi encontrado risco aumentado de câncer gástrico em asiáticos sob o modelo de alelo ( $\mathrm{G}$ vs A: $\mathrm{OR}=1.520,95 \% \mathrm{CI}=1.172-1.973 ; P=0.002)$, modelo heterozigoto $(\mathrm{GG}+\mathrm{GA}$ vs AA: $\mathrm{OR}=1.571,95 \% \mathrm{CI}=1.023-2.414 ; P=0.039)$, e modelo dominante $(\mathrm{GG}+\mathrm{GA}$ vs $\mathrm{AA}: \mathrm{OR}=1.448,95 \% \mathrm{CI}=1.152-1.821$; $P=0.002$ ), mas não entre a população caucasiana e latina. Conclusão - Estes resultados sugeriram que a IL-10-1082 A/polimorfismo G (rs1800896) pode contribuir para a suscetibilidade de câncer gástrico, especialmente entre os asiáticos.

DESCRITORES - Neoplasias gástricas. Interleucina-10. Polimorfismo genético. Metanálise.

\section{REFERENCES}

1. Jiang B, Zhu K, Shao H, Bao C, Ou J, Sun W. Lack of association between the CDH1 polymorphism and gastric cancer susceptibility: a meta-analysis. Sci Rep. 2015;5:7891.

2. Khoram-Abadi KM, Forat-Yazdi M, Kheirandish S, Saeidi N, Zarezade Z, Mehrabi N, Neamatzadeh H. DNMT3B -149 C > T and -579 G > T Polymorphisms and Risk of Gastric and Colorectal Cancer: a Meta-analysis. Asian Pac J Cancer Prev. 2016;17:3015-20.

3. Forman D, Burley VJ. Gastric cancer: global pattern of the disease and an overview of environmental risk factors. Best Pract Res Clin Gastroenterol. 2006;20:633-49.

4. Rahman R, Asombang AW, Ibdah JA. Characteristics of gastric cancer in Asia. World J Gastroenterol. 2014;20:4483-90.

5. Kim Y, Park J, Nam B-H, Ki M. Stomach cancer incidence rates among Americans, Asian Americans and Native Asians from 1988 to 2011. Epidemiology and Health. 2015;37:e2015006.

6. Sahami-Fard MH, Yazd EF, Khazaei Z, Neamatzadeh H. Lack of Association between the CDH1 -160C $>$ A Polymorphism and Risk of Gastrointestinal Cancer - a Meta-Analysis. Asian Pac J Cancer Prev. 2016;17:2415-21.

7. Qin XP, Zhou Y, Chen Y, Li NN1, Wu XT. XRCC3 Thr241Met polymorphism and gastric cancer susceptibility: A meta-analysis. Clin Res Hepatol Gastroenterol. 2014;38:226-34.

8. Kargar S, Shiryazdi SM, Atashi SR, Neamatzadeh H, Kamali M. Urinary Iodine Concentrations in Cancer Patients. Asian Pac J Cancer Prev. 2017;18:819-21.

9. Compare D, Rocco A, Nardone G. Risk Factors in Gastric Cancer. Eur Rev Med Pharmacol Sci. 2010;14:302-8.

10. McLean MH, El-Omar EM. Genetics of gastric cancer. Nat Rev Gastroenterol Hepatol. 2014;11:664-74.

11. Lech-Maranda E, Baseggio L, Bienvenu J, Charlot C, Berger F, Rigal D, et al. Interleukin-10 gene promoter polymorphisms influence the clinical outcome of diffuse large B-cell lymphoma. Blood. 2004;103:3529-34.

12. Tanikawa T, Wilke CM, Kryczek I, Chen GY, Kao J, Núñez G, et al. Interleukin (IL)-10 ablation promotes tumor development, growth and metastasis. Cancer Research. 2012;72:420-9.

13. Matsumoto K, Oki A, Satoh T, Okada S, Minaguchi T, Onuki M, et al. Interleukin-10 -1082 gene polymorphism and susceptibility to cervical cancer among Japanese women. Jpn J Clin Oncol. 2010;40:1113-6.

14. Li YF, Yang PZ, Li HF. Functional polymorphisms in the IL-10 gene with susceptibility to esophageal, nasopharyngeal, and oral cancers. Cancer Biomark. 2016;16:641-51.

15. Cacev $T$, Radosević $S$, Krizanac $S$, Kapitanović $S$. Influence of interleukin- 8 and interleukin-10 on sporadic colon cancer development and progression. Carcinogenesis. 2008;29:1572-80.

16. Wu LM, Zhou L, Xu J, Wei BJ, Cheng J, Xu X, et al. Lack of association between genetic polymorphisms in cytokine genes and tumor recurrence in patients with hepatocellular carcinoma undergoing transplantation. Hepatobiliary Pancreat Dis Int. 2013:12:54-9.

17. Ni P, Xu H, Xue H, Lin B, Lu Y. A meta-analysis of interleukin-10-1082 promoter polymorphism associated with gastric cancer risk. DNA Cell Biol. 2012;31:582-91.
18. Mehdinejad M, Sobhan MR, Mazaheri M, Zare Shehneh M, Neamatzadeh H, Kalantar SM. Genetic Association between ERCC2, NBN, RAD51 Gene Variants and Osteosarcoma Risk: a Systematic Review and Meta-Analysis. Asian Pac J Cancer Prev. 2017;18:1315-21.

19. Sobhan MR, Forat Yazdi M, Mazaheri M, Zare Shehneh M, Neamatzadeh H Association between the DNA Repair Gene XRCC3 rs861539 Polymorphism and Risk of Osteosarcoma: a Systematic Review and Meta-Analysis. Asian Pac J Cancer Prev. 2017;18:549-55.

20. Mantel N, Haenszel W. Statistical aspects of the analysis of data from retrospective studies of disease. J Natl Cancer Inst. 1959;22:719-48.

21. DerSimonian R. Meta-analysis in the design and monitoring of clinical trials. Stat Med 1996;15:1237-1248, discussion 1249-52.

22. Begg CB, Mazumdar M. Operating characteristics of a rank correlation test for publication bias. Biometrics. 1994;50:1088-101.

23. Kim J, Cho YA, Choi IJ, Lee YS, Kim SY, Shin A, et al. Effects of interleukin-10 polymorphisms, Helicobacter pylori infection, and smoking on the risk of noncardia gastric cancer. PLoS One. 2012;7:e29643.

24. Egger M, Davey SG, Schneider M, Minder C. Bias in meta-analysis detected by a simple, graphical test. BMJ 1997;315: 629-34.

25. Ko KP, Park SK, Cho LY, Gwack J, Yang JJ, Shin A, et al. Soybean product intake modifies the association between interleukin-10 genetic polymorphisms and gastric cancer risk. J Nutr. 2009;139:1008-12

26. Kumar S, Kumari N, Mittal RD, Mohindra S, Ghoshal UC. Association between pro-(IL-8) and anti-inflammatory (IL-10) cytokine variants and their serum levels and H. pylori-related gastric carcinogenesis in northern India. Meta Gene. 2015;6:9-16.

27. Kuo WH, Huang CY, Fu CK, Hsieh YH, Liao CH, Hsu CM, Huang YK, Tsai $\mathrm{CW}$, Chang WS, Bau DT. Effects of www.impactjournals.com/oncotarget 18 Oncotarget interleukin-10 polymorphisms and smoking on the risk of gastric cancer in Taiwan. In Vivo. 2014;28:967-71.

28. Lee JY, Kim HY, Kim KH, Kim SM, Jang MK, Park JY, Lee JH, Kim JH, Yoo JY. Association of polymorphism of IL-10 and TNF-A genes with gastric cancer in Korea. Cancer Lett. 2005;225:207-14.

29. Liu J, Song B, Wang JL, Li ZJ, Li WH, Wang ZH. Polymorphisms of interleukin-10 promoter are not associated with prognosis of advanced gastric cancer. World J Gastroenterol. 2011;17:1362-7.

30. Lu W, Pan K, Zhang L, Lin D, Miao X, You W. Genetic polymorphisms of interleukin (IL)-1B, IL-1RN, IL-8, IL-10 and tumor necrosis factor $\alpha$ and risk of gastric cancer in a Chinese population. Carcinogenesis. 2005;26:631-6.

31. Minelli C, Thompson JR, Abrams KR, Thakkinstian A, Attia J. How should we use information about HWE in the meta-analyses of genetic association studies? Int J Epidemiol. 2008:37:136-46.

32. Morgan DR, Dominguez RL, Keku TO, Heidt PE, Martin CF, Galanko JA, et al. Gastric cancer and the high combination prevalence of host cytokine genotypes and Helicobacter. Clin Gastroenterol Hepatol. 2006;4:1103-11.

33. Pan XF, Yang SJ, Loh M, Xie Y, Wen YY, Tian Z, et al. Interleukin-10 gene promoter polymorphisms and risk of gastric cancer in a Chinese population: single nucleotide and haplotype analyses. Asian Pac J Cancer P. 2013;14:2577-82. 
34. Savage SA, Abnet CC, Haque K, Mark SD, Qiao YL, Dong ZW, Dawsey SM, Taylor PR, Chanock SJ. Polymorphisms in interleukin -2, -6, and -10 are not associated with gastric cardia or esophageal cancer in a high-risk Chinese population. Cancer Epidemiol Biomarkers Prev. 2004;13:1547-9.

35. Shin CM, Kim N, Lee HS, Lee DH, Kim JS, Jung HC, Song IS. Intrafamilial aggregation of gastric cancer: a comprehensive approach including environmental factors, Helicobacter pylori virulence, and genetic susceptibility. Eur J Gastroenterol Hepatol. 2011;23:411-7.

36. Sugimoto M, Furuta T, Shirai N, Nakamura A, Kajimura M, Sugimura H Hishida A. Effects of interleukin- 10 gene polymorphism on the development of gastric cancer and peptic ulcer in Japanese subjects. J Gastroenterol Hepatol 2007;22:1443-9.

37. Wu MS, Huang SP, Chang YT, Shun CT, Chang MC, Lin MT, Wang HP, Lin JT. Tumor necrosis factor-alpha and interleukin-10 promoter polymorphisms in Epstein-Barr virus-associated gastric carcinoma. J Infect Dis. 2002;185:106-9.

38. Wu MS, Wu CY, Chen CJ, Lin MT, Shun CT, Lin JT. Interleukin-10 genotypes associate with the risk of gastric carcinoma in Taiwanese Chinese. Int J Cancer. 2003;104:617-23.

39. Xiao H, Jiang Y, Li R, Xia B. Association of IL-10 gene polymorphisms with gastroduodenal diseases in Hubei Han population. Zhonghua Yi Xue Yi Chuan Xue Za Zhi. 2009;26:423-6.

40. Bai XL, Sun LP, Liu J, Chen W, Zhang Y, Yuan Y. [Correlation of interleukin-10-1082G/A single nucleotide polymorphism to the risk of gastric cancer in North China: a case-control study]. [Article in Chinese]. Ai Zheng. 2008;27:35-40.

41. Chand-Bhayal A, Krishnaveni D, Pandu-Ranga-Rao K, Prabhakar B, Vidyasagar A, Murali-Krishna B, et al. Association of interleukin-10 promoter polymorphism (-1082 g/a) and gastric cancer in andhra pradesh population of South India. Iran J Cancer Prev. 2012;5:117-23.

42. Guo W, Wang N, Wang YM, Li Y, Wen DG, Chen ZF, He YT, Zhang JH. Interleukin-10-1082 promoter polymorphism is not associated with susceptibility to esophageal squamous cell carcinoma and gastric cardiac adenocarcinoma in a population of high-incidence region of north China. World J Gastroenterol. 2005;11:858-62.

43. He B, Pan Y, Xu Y, Nie Z, Chen L, Gu L, Wang S. Increased risk for gastric cancer in carriers of the lymphotoxin- $\alpha+252 \mathrm{G}$ variant infected by Helicobacter pylori. Genet Test Mol Biomarkers. 2012;16:9-14.

44. Kang JM, Kim N, Lee DH, Park JH, Lee MK, Kim JS, et al. The effects of genetic polymorphisms of IL-6, IL-8, and IL-10 on Helicobacter pylori-induced gastroduodenal diseases in Korea. J Clin Gastroenterol. 2009;43:420-8.
45. Zeng X, Li Y, Liu T, Zhang J. Diverse H. pylori strains, IL-10 promoter polymorphisms with high morbidity of gastric cancer in Hexi area of Gansu Province, China. Mol Cell Biochem. 2012;362:241-8.

46. Zhou SZ, Zhu WL, Li MY, Li HY, Zhang JR. [Association of single nucleotide polymorphism at interleukin-10 gene $1082 \mathrm{nt}$ with the risk of gastric cancer in Chinese population]. [Article in Chinese]. Nan Fang Yi Ke Da Xue Xue Bao. 2008;28:1335-8.

47. Burada F, Angelescu C, Ioana M, Mitrut P, Moraru E, Riza A, et al. IL-10 -1082 A/G polymorphism and risk of gastric cancer. Annals of RSCB; 2010. Vol. XV, Issue 1.

48. El-Omar EM, Rabkin CS, Gammon MD, Vaughan TL, Risch HA, Schoenberg JB, et al. Increased risk of noncardia gastric cancer associated with proinflammatory cytokine gene polymorphisms. Gastroenterology. 2003;124:1193-201.

49. Forte GI, Calà C, Scola L, Crivello A, Gullo A, Marasà L, et al. Role of environmental and genetic factor interaction in age-related disease development: the gastric cancer paradigm. Rejuvenation Res. 2008;11:509-12.

50. García-González MA, Lanas A, Quintero E, Nicolás D, Parra-Blanco A, Strunk $\mathrm{M}$, et al Gastric cancer susceptibility is not linked to pro-and anti-inflammatory cytokine gene polymorphisms in whites: a Nationwide Multicenter Study in Spain. Am J Gastroenterol. 2007;102:1878-92.

51. Kamangar F, Abnet CC, Hutchinson AA, Newschaffer CJ, Helzlsouer K, Shugar YY, et al. Polymorphisms in inflammation-related genes and risk of gastric cancer (Finland). Cancer Causes Control. 2006;17:117-25.

52. Zambon CF, Basso D, Navaglia F, Belluco C, Falda A, Fogar P, et al. Pro- and anti-inflammatory cytokines gene polymorphisms and Helicobacter pylor infection: interactions influence outcome. Cytokine. 2005;29:141-52.

53. Alpízar-Alpízar W, Pérez-Pérez GI, Une C, Cuenca P, Sierra R. Association of interleukin-1B and interleukin-1 RN polymorphisms with gastric cancer in a high-risk population of Costa Rica. Clin Exp Med. 2005;5:169-76.

54. Gonzalez-Hormazabal P, Musleh M, Bustamante M, Stambuk J, Escandar S, Valladares $\mathrm{H}$, et al. Role of cytokine gene polymorphisms in gastric cancer risk in Chile. Anticancer Res. 2014;34:3523-30.

55. Kamali M, Hantoushzadeh S, Borna S, Neamatzadeh H, Mazaheri M, Noori-Shadkam M, Haghighi F. Association between Thrombophilic Genes Polymorphisms and Recurrent Pregnancy Loss Susceptibility in the Iranian Population: a Systematic Review and Meta-Analysis. Iran Biomed J. 2018;22:78-89.

56. Namazi A, Abedinzadeh M, Nourbaksh P, Neamatzadeh H. Association between the XRCC3 Thr241Met polymorphism and risk of colorectal cancer: a meta-analysis of 5,193 cases and 6,645 controls. Asian Pac J Cancer Prev. $2015 ; 16: 2263-8$ 